\title{
Narrativas de mulheres sobre o enfrentamento à violência na saúde
}

\section{Women's narratives about coping violence in health care}

\section{Narrativas de las mujeres sobre el enfrentamiento de la violencia en la salud}

\author{
Jorge Lyra $^{a} \mathbb{D}^{\mathbb{D}}$; Benedito Medrado ${ }^{\mathrm{b}} \mathbb{D}^{\mathbb{D}}$; Mirella de Lucena Mota $^{\mathrm{C}} \mathbb{D}^{\mathbb{D}}$; Jorge Luiz Silva ${ }^{\mathrm{d}} \mathbb{D}^{\mathbb{D}}$; \\ Patricia Ivanca ${ }^{\mathrm{e}}$
}

a Mestre em Psicologia Social e Doutor em Saúde Pública. Professor do Departamento de Psicologia da UFPE. Recife, PE, Brasil E-mail: jorglyra@gmail.com

b Doutor em Psicologia Social. Professor do Departamento de Psicologia da UFPE, Recife, PE, Brasil - E-mail: beneditomedrado@gmail.com

c Mestra em Psicologia pelo Programa de Pós-Graduação em Psicologia (PPGPsi/UFPE). Doutoranda pelo Programa de PósGraduação em Serviço Social (PPGSS/UFPE), Recife, PE, Brasil - E-mail: mirelladelucena@gmail.com

d Doutorando e Mestre em Psicologia pelo Programa de Pós-Graduação em Psicologia da Universidade Federal de Pernambuco (UFPE). Psicólogo Residente no Programa de Residência Multiprofissional em Saúde Mental pela Universidade de Pernambuco (UPE), Recife, PE, Brasil - E-mail: jorgew.lds@gmail.com

e Graduada em Psicologia pela Universidade de Pernambuco - Campus Garanhuns/PE (UPE), mestra em Psicologia pelo Programa de Pós-Graduação em Psicologia (PPGPsi/UFPE), Recife, PE, Brasil - E-mail: ivancapatricia@gmail.com

Resumo: A violência contra as mulheres, entendida como produto das desigualdades de gênero, interseccionada com questões de raça e classe tomou uma importância crescente no mundo e no Brasil ao longo das últimas décadas. Sendo assim, com o objetivo de compreender as ações de enfrentamento à violência contra as mulheres no contexto da atenção primária a saúde entrevistamos 15 mulheres usuárias dos serviços em Recife/ Pernambuco. Organizamos os resultados a partir de quatro categorias: concepções de violência contra as mulheres, motivações para as situações de violência, estratégias de enfrentamento às violências contra as mulheres e atenção às violências contra as mulheres nas Unidades de Saúde da Família. Este trabalho nos levou a refletir sobre a necessidade e importância de que deve haver a discussão da temática da violência contra as mulheres dentro das USF e o reconhecimento que essas unidades são o primeiro lugar que as mulheres buscam para realização do cuidado.

Palavras-chave: Atenção primária à saúde. Saúde da mulher. Violência contra a mulher.

\begin{abstract}
Violence against women, understood as a product of gender inequalities, intersected with race and class issues, has become increasingly important in the world and in Brazil over the last decades. Thus, in order to understand the actions to combat violence against women in the context of primary health care, we interviewed 15 women users of the services in Recife, Pernambuco. We organized the results from four categories: conceptions of violence against women, motivations for situations of violence, coping strategies against violence against women and attention to violence against women in Family Health Units. This work has led us to reflect on the need and importance of discussing the issue of violence against women within USF and the recognition that these units are the first place that women seek to perform care.
\end{abstract}

Keywords: Primary healthcare. Women's health. Violence against women. obra, forneça um link para a licença, e indicar se foram feitas alterações. 
Resumen: La violencia contra las mujeres, entendida como producto de las desigualdades de género, interseccionada con cuestiones de raza y clase, ha tomado una importancia creciente en el mundo y en Brasil a lo largo de las últimas décadas. Por lo tanto, con el objetivo de comprender las acciones de enfrentamiento a la violencia contra las mujeres en el contexto de la atención primaria la salud entrevistamos a 15 mujeres usuarias de los servicios en Recife, Pernambuco. Organizamos los resultados a partir de cuatro categorías: concepciones de violencia contra las mujeres, motivaciones para las situaciones de violencia, estrategias de enfrentamiento a las violencias contra las mujeres y atención a las violencias contra las mujeres en las Unidades de Salud de Familia. Este trabajo nos llevó a reflexionar sobre la necesidad e importancia de que debe haber la discusión de la temática de la violencia contra las mujeres dentro de las USF y el reconocimiento que esas unidades son el primer lugar que las mujeres buscan para la realización del cuidado.

Palabras clave: Atención primaria a la salud. Salud de la mujer. Violencia contra la mujer

\section{Como citar o artigo:}

LYRA, Jorge. et al. Narrativas de mulheres sobre o enfrentamento à violência na saúde. Revista de Ciências Humanas, Florianópolis, v. 52, 2018 DOI: 10.5007/2178-4582.2018.56954

\section{INTRODUÇÃO}

A violência contra as mulheres, entendida como produto das desigualdades de gênero, interseccionada com questões de raça e classe, tomou uma importância crescente no mundo e no Brasil ao longo das últimas décadas. A partir da luta dos movimentos feministas e das determinações dos Organismos Internacionais, configurou-se como uma questão de políticas públicas, ganhando força nas décadas de 1970 e 1980, com formulações dos Direitos Humanos (SCHRAIBER, 2001; AZAMBUJA, 2008).

No Brasil, o reconhecimento da violência contra as mulheres como uma questão de saúde foi anterior às formulações internacionais, já se encontrando em pauta desde os anos 80 com a formulação do Programa de Atenção Integral à Saúde das Mulheres (PAISM) em 1983 (KRUG et al., 2002). O PAISM inspirou outros programas, normas técnicas e planos com o objetivo de qualificar os/as profissionais do SUS e, portanto, garantir o exercício pleno dos direitos humanos das mulheres, base de uma saúde pública de fato universal, integral e equânime (BRASIL, 2004).

Nesse sentido, os serviços de atenção primária à saúde apresentam-se estratégicos para lidar com a temática, tendo em vista que representam o primeiro acesso das mulheres ao setor saúde e oferecem um acompanhamento de base territorial e comunitária ao longo de toda a vida das usuárias. É destinado a responder pelos problemas mais comuns de saúde, destacando a atenção à família em seu contexto de vida e tem como prioridade não apenas as ações de cura, mas também de prevenção e promoção à saúde (BRASIL, 2012). Assim, faz-se necessário pensar estratégias e práticas de cuidado acolhedoras e sensíveis às questões da violência contra as mulheres no âmbito da atenção primária.

Acolher significa dar acolhida, admitir, aceitar, dar ouvidos, dar créditos, agasalhar, receber, atender, admitir. $\mathrm{O}$ acolhimento como ato ou efeito de acolher significa, portanto, uma ação de 
aproximação, uma atitude de inclusão (BRASIL, 2010). Significa reconhecer as necessidades das usuárias, ampliando a oferta de serviços a fim de fazer com que a usuária se sinta protegida e perceba que o serviço procurado está preparado e aberto para dar conta de suas demandas.

Porém, apesar das Unidades de Saúde da Família (USF) serem estratégicas no enfrentamento às questões de violência contra as mulheres, muitos serviços de saúde ainda encontram desafios para integrar o atendimento às situações de violência contra as mulheres à sua rotina de atendimentos do serviço. A assistência e os cuidados em saúde, de modo geral, demonstram dificuldades em lidar com problemas identificados como sociais e subjetivos. Muitos profissionais da saúde lidam mal com demandas que nem sempre se caracterizam como adoecimentos, mesmo que indiquem sofrimentos e necessidades de saúde da população assistida (SCHRAIBER, 2001).

Diante desse contexto, este trabalho tem como finalidade compreender como vem se dando o acolhimento às mulheres em situação de violência em Unidades de Saúde da Família da cidade do Recife. É produto de uma pesquisa mais ampla sobre o enfrentamento à violência contra as mulheres na atenção primária à saúde, que compreendeu a realização de observações no cotidiano das USF e o diálogo com mulheres usuárias dos serviços sobre saúde e violência.

\section{TECENDO REDES PARAA COMPREENSÃO DO FENÔMENO DA VIOLÊNCIA CONTRA} AS MULHERES

A desigualdade de gênero coloca as mulheres em posições de subordinação, o fenômeno da violência contra as mulheres e a violência de gênero têm influenciado os modos de vida das mulheres, ocasionando adoecimento e morte. Essa desigualdade permite que a violência se coloque como mecanismo de controle, de poder e de força nas relações pessoais e familiares (GUEDES; SILVA; FONSECA, 2009; RODRIGUES et al., 2012).

No estudo realizado por Lima et al. (2013), foi identificado que as mulheres em situação de violência participantes da pesquisa apresentaram uma média da autoestima satisfatória, mas que estes dados variam de acordo com a presença ou não do agressor na vida delas. Observou-se também que a baixa autoestima pode estar associada à valorização, respeito do agressor e a dependência emocional e financeira pelo companheiro.

Vieira et al. (2011), revelam a importância de estudos que busquem compreender as realidades vivenciadas pelas mulheres que denunciam situações de violência, a partir de uma perspectiva que considere aspectos da vida cotidiana, com aproximações compreensivas, levando em conta as demandas das mulheres a partir de uma visão de totalidade e de uma contextualização sócio histórica e situada na cultura. 
Para tanto, é necessário ampliar o olhar sobre a questão da violência, para além dos aspectos biológicos e das clássicas intervenções físicas no setor saúde. Essa prática requer compreender a rede de relações sociais que a mulher estabelece, seja com o/a companheiro/a, os/as filhos/as, profissionais etc. (VIEIRA et al., 2011).

Dessa forma, torna-se importante que o atendimento da equipe de saúde possa ir além dos cuidados médico-curativos, compreendendo o contexto no qual a mulher está inserida e realizando encaminhamentos adequados.

Os achados de Moraes, Arana e Reichenheim (2010) também apontam para a necessidade de cuidado integral e sistemático que englobe os aspectos psicossociais e não se restringe a procedimentos e exames tradicionais associados à gestação. Segundo Schraiber, D'Oliveira e Couto (2006), a não identificação do fenômeno da violência durante os diagnósticos relaciona-se às dificuldades das mulheres na revelação do vivido, essa dificuldade é reforçada em muitos casos pelo descrédito e julgamento moral dos profissionais que as escutam.

Foi através da implantação de um serviço de saúde, no final dos anos 80 , que o tema da violência contra as mulheres começou a ser debatido no setor saúde em nosso país. Tal serviço, que tinha como finalidade realizar abortos de acordo com a prescrição constitucional ${ }^{1}$, acabou por desvelar uma limitação no entendimento do fenômeno da violência, focando-se na violência sexual e por agressor desconhecido. No entanto, muitas das violências cometidas contra as mulheres são de outras ordens, como psicológica, patrimonial e institucional, e geralmente os agressores são parceiros íntimos ou da rede pessoal (D’OLIVEIRA et al., 2009).

Apesar da opressão e violência sofrida pelas mulheres violar seus direitos sexuais, tal forma de violência ainda é legitimada socialmente, passando a operar a negação do direito sexual feminino e a dominação pelo parceiro sobre o corpo e o desejo da mulher (GUEDES; SILVA; FONSECA, 2009).

Guedes, Silva e Fonseca (2009) se preocuparam em estudar o fenômeno da violência a partir de depoimentos de mulheres que denunciavam a violência sofrida, com o recorte na violência conjugal. Este tipo de violência, de acordo com as autoras, tem sido uma forma prevalecente, com característica de recorrência e escalas crescentes de gravidade.

Estudos de Moraes, Arana e Reichenheim (2010) sugerem que a violência doméstica, além de afetar biologicamente a saúde reprodutiva da mulher, é um fator que influencia para uma má qualidade do pré-natal. De acordo com esses estudos, é possível postular que a vivência de relações íntimas violentas possa influenciar o perfil reprodutivo, aumentando o número de filhos vivos e

${ }^{1}$ Casos de estupro e risco de vida para a mulher. 
reduzindo o tempo de intervalo entre partos, dificultando a adesão das gestantes aos serviços de saúde e, consequentemente, violando seus direitos reprodutivos.

D’Oliveira et al. (2009), apontam a importância de investigar a violência nos serviços de saúde, para que o fenômeno e a situação possam ser melhor compreendidos, físico, emocional e socialmente, e melhores estratégias e práticas de cuidado integral possam ser desenvolvidas.

Diante de tamanha complexidade que a vivência da violência acarreta para as mulheres, é importante compreender quais as dificuldades experimentadas pelas mesmas na busca por cuidado. Assim, conhecer seus trajetos nas redes de apoio pode ser uma estratégia para a garantia de um atendimento integral e contextualizado nos distintos serviços de apoio à rede de enfrentamento à violência contra as mulheres. A rota crítica pode ser entendida como "uma série de fatores facilitadores e inibidores da decisão de romper com as violências” (MENEGHEL et al., 2011, p. 749).

Em estudo que buscou identificar a rota crítica de mulheres em situações de violência em Porto Alegre, as mulheres identificaram como facilitadores a Lei $\mathrm{n}^{\circ} 11.340$, de 7 de agosto de 2006 (Lei Maria da Penha), bem como o atendimento de alguns profissionais e a agilidade de alguns procedimentos; como limitadores, as mulheres apontaram a dificuldade de compreensão das orientações e processos, a fragmentação dos serviços, a ausência de um centro de atendimento integral e ainda a pressão de operadores jurídicos para que permaneçam na relação conjugal e também a dificuldade de ter as medidas protetivas asseguradas pela polícia (MENEGHEL et al., 2011)

Nesse contexto, a USF pode ser o principal elo entre a comunidade e a Rede de Enfrentamento à Violência Contra a Mulher. A USF pode ainda ser exemplo de combate à violência institucional, através da estimulação da integralidade da atenção, do desenvolvimento de práticas de não violência, recusando-se a reproduzi-la em seu interior, para, com isso, torná-la visível (D'OLIVEIRA et al., 2009).

Nesse sentido, a atenção primária à saúde parece ser um lócus privilegiado para tratar de questões relacionadas à violência contra as mulheres, já que além de seu foco ser em ações de prevenção e promoção de saúde, sua localização facilita a inserção comunitária e o desenvolvimento de relações de maior confiança entre os profissionais e as moradoras do bairro, com a solidificação da Estratégia de Saúde da Família (D’OLIVEIRA et al., 2009).

Como dizem Vianna, Bomfim e Chicone (2006), a Unidade de Saúde da Família, por estar inserida no cotidiano da comunidade, deve tratar o tema da violência sem temor e publicamente, podendo ser feito através da comunicação por cartazes e da distribuição de folhetos nas unidades.

Outra estratégia é a realização de palestras e/ou grupos para a discussão da temática, como algumas das unidades visitadas realizam com hipertensão e diabetes, reconhecendo que essas práticas podem facilitar a revelação de casos de violência na comunidade, uma vez que, de acordo com Soares, 
Lopes e Njaine (2013), mulheres que vivenciam situações de violência frequentemente apresentam maior dificuldade em acessar os serviços de saúde.

Por outro lado, Schraiber, Barros e Castilho (2010) apresentam que mulheres que sofrem violência doméstica procuram mais vezes os serviços de saúde que o restante da população, principalmente no que se refere a episódios recorrentes de violência. Esse mesmo estudo mostra que há um uso muito maior da atenção primária à saúde em relação a outros serviços e que mulheres que convivem com violência repetitiva por parceiros íntimos apresentam maior frequência de uso de serviços de saúde e de agravos à saúde, em especial problemas de saúde mental.

A procura pelos serviços da atenção primária é maior durante o período em que a mulher sofre violência e diminui após a cessação. Porém, estudos de Rivara et al. (2007), apontaram que mesmo após cinco anos do fim dos episódios de violência, as mulheres com história pregressa continuaram apresentando taxas elevadas de procura por serviços de saúde mental, serviços para controle de uso de álcool e outras drogas, ambulatórios hospitalares e serviços de emergência, exceto internações.

Diante disso, Schraiber et al. (2007) aponta para o quanto os serviços de atenção primária são importantes para as mulheres que sofrem violência por parceiros íntimos e para a relevância do aprimoramento da atenção para a saúde dessas mulheres. Ela também sinaliza para a necessidade de implantação de ações que extrapolem os cuidados aos agravos à saúde da mulher de forma particular, mas principalmente previnam e lidem com a violência de forma global.

Na pesquisa realizada por Guedes, Fonseca e Egry (2013), os autores encontraram que os espaços de reconhecimento de violência se traduzem em lugares frequentados pelas mulheres com demandas de saúde. No que se refere a situações de violência vivenciadas pelas mulheres, essas raramente aparecem de forma imediata no serviço, sendo expressas como demanda implícita.

Passados quatorze anos do relatório da Organização Mundial da Saúde sobre violência e saúde, já é de conhecimento dos/as profissionais que a violência contra as mulheres causa impactos de ordem física e mental. Sabe-se também que as mulheres podem recorrer aos serviços de saúde com demandas diretamente relacionadas às violências, como fraturas, tentativas de aborto, de suicídio ou com sofrimentos e demandas menos específicas e mais dificilmente compreensíveis, como doenças crônicas e transtornos depressivos e/ou ansiosos (D’OLIVEIRA et al., 2009).

Apesar da ampla circulação dessas informações, reconhecer situações de violência que deixam marcas menos evidentes, e provocadas por companheiros, ainda é muito difícil nos serviços de atenção primária à saúde, pois a maioria dos serviços é carente de profissionais especializados no reconhecimento de sinais de violência (VIANNA; BOMFIM; CHICONE, 2006).

Ilha, Leal e Soares (2010) buscaram caracterizar a hospitalização de mulheres vítimas de agressão em um Hospital de Porto Alegre/RS durante o ano de 2005. Nesta pesquisa foi evidenciado 
que algumas informações importantes, muitas vezes, são subnotificadas, como motivo da agressão e caracterização do agressor. Os registros incompletos e/ou inexistentes contribuem com a invisibilidade da violência contra as mulheres, em especial aquelas que são acometidas pelos parceiros íntimos.

Facuri et al. (2013), também identificaram a subnotificação dos casos de violência, em particular os Boletins de Ocorrência relativos à violência sexual. A baixa notificação policial pode contribuir para uma distorção da realidade e a estruturação/implementação adequada de políticas públicas para o enfrentamento da violência contra as mulheres.

Para tanto, a detecção é a primeira tarefa a cumprir, ainda que, para Vianna, Bomfim e Chicone (2006), ela dependa da confiança que os profissionais têm de que poderão executar práticas assistenciais da melhor qualidade, baseadas especialmente na interdisciplinaridade e na intersetorialidade. Essa etapa é de fundamental importância, pois frequentemente, tanto as mulheres quanto os profissionais tendem a banalizar os relatos, desconsiderando-os como violência ou tratando-os como sendo de responsabilidade única da justiça.

De acordo com Soares, Lopes e Njaine (2013), as estratégias para enfrentamento das múltiplas violências cometidas contra as mulheres devem ser construídas sob a ótica da valorização da integração comunitária. E a finalidade do trabalho contra as violências deve caminhar em direção ao empoderamento das mulheres, sua emancipação e autonomia, não apenas o tratamento dos sintomas e a resolução das queixas com práticas de medicalização, reorientando a base do trabalho do profissional de saúde.

\section{METODOLOGIA}

Este texto é fruto das reflexões e estudos desenvolvidos pelo Núcleo Feminista de Pesquisas em Gênero e Masculinidades (GEMA/UFPE) no projeto de pesquisa "Avaliação da atenção a mulheres em situação de violência na rede de atenção básica em saúde no município de Recife", apoiado pela Fundação de Amparo a Pesquisa de Pernambuco (FACEPE) ${ }^{2}$.

Os resultados apresentados aqui foram originários das idas à campo a unidades de saúde da família no Recife, onde entrevistamos mulheres usuárias dos serviços a fim de compreender as ações de enfrentamento à violência contra as mulheres no contexto da atenção primária. Para a discussão deste texto, foi feito o recorte da análise sobre como essas mulheres buscam e avaliam os serviços de saúde em relação à atenção prestada.

\footnotetext{
${ }^{2}$ Edital: APQ - 13/2012 - pesquisa para o SUS: gestão compartilhada em saúde PPSUS - REDE MS/CNPQ/FACEPE/SES - $2^{\mathrm{a}}$ rodada. Processo No: APQ - 0023-4.00/13
} 
Para a entrevista com as mulheres, os/as pesquisadores/as, organizados/as em duplas, realizaram em torno de 10 idas à campo, chegando a entrevistar 15 mulheres em duas comunidades distintas, utilizando como inspiração a ferramenta da entrevista episódica de Flick (2002). Tal abordagem visa aproximar o objeto de estudo com a realidade de vida das interlocutoras da pesquisa, retomando experiências que são trazidas pelas mulheres, gerando narrativas.

Geralmente iniciávamos com a seguinte pergunta: você poderia me relatar como é um dia de atendimento na unidade de saúde? A partir daí a entrevista ocorria sempre procurando retomar as experiências das mulheres, estabelecendo trocas entre entrevistador/a e entrevistada. $\mathrm{O}$ campo nos falava e nos questionava, sendo possível também criar relações e estratégias para a viabilização da pesquisa. Como por exemplo, enquanto um/a pesquisador/a facilitava a entrevista outro/a pesquisador/a aguardava a chamada da usuária para o atendimento, para que a usuária não perdesse o mesmo.

Tivemos também o apoio dos/as profissionais das duas unidades de saúde onde realizamos as entrevistas, desde a disponibilização de salas, convite para participar de um grupo de saúde mental promovido pela unidade no espaço de um salão paroquial, até à conversa dos/as profissionais com as usuárias sobre a proposta da pesquisa, o que facilitava nosso acesso devido à relação de vínculo estabelecido.

Vale ressaltar que a disponibilidade das mulheres entrevistadas foi de extrema importância. Pois, diante da correria do cotidiano, com inúmeras atividades e responsabilidades atribuídas às mulheres na função de cuidadora, muitos poderiam ser os nãos que receberíamos, mas ao contrário, a participação e interesse das mulheres sobre o tema, bem como a abertura que tivemos foi essencial para a realização da pesquisa.

Para analisar os dados, foi utilizada uma metodologia de inspiração construcionista, baseada nos textos de Spink (2010) sobre mapas dialógicos e linhas narrativas, de Spink e Lima (2013) a respeito do rigor e da visibilidade de dados na explicitação do processo de interpretação, de Medrado e Lyra (2015) sobre estratégias de análise na pesquisa qualitativa, e de Nascimento, Tavanti e Pereira (2014), onde compartilham seus usos de mapas dialógicos como recurso analítico em pesquisas científicas.

Após as leituras e discussões desses textos, determinamos que o processo de análise se daria em quatro momentos: 1) realização de transcrições sequenciais; 2) estabelecimento das categorias de análise; 3) a construção de mapas dialógicos; e 4) o cruzamento das narrativas com a literatura a respeito do tema, pensando nas várias realidades experimentadas e organizadas pelas mulheres.

A etapa inicial foi a realização de transcrições sequenciais, nas quais, diferentes das transcrições integrais, não são transformadas em texto todas as falas da entrevista, mas sim 
identificados o tema sobre o qual se fala (a cada sentença) e como a conversa acontece. Adotamos esse processo por acreditar que facilitaria a produção das categorias analíticas, uma vez que poderíamos facilmente identificar os "temas" mais comuns nas diferentes entrevistas.

A seguir, após inúmeras leituras e oitivas, partimos para a produção conjunta das categorias de análise, que, de acordo com Spink (2010), já compreende a continuidade do processo de análise. Continuidade porque, nessa lógica, o processo de análise já se iniciou em um momento muito anterior às reuniões para a (des)organização dos caminhos analíticos a serem seguidos, talvez nas inspirações que cada uma experimentava após os encontros com as interlocutoras. Para o estabelecimento de tais categorias foram cruzados os objetivos da pesquisa, os roteiros elaborados para as entrevistas, e, principalmente, as narrativas das interlocutoras, respeitando sua integralidade.

Foram produzidas quatro categorias, a saber: 1) Concepções de violência contra as mulheres; 2) motivações para as situações de violência; 3) estratégias de enfrentamento às violências contra as mulheres; e 4) atenção às violências contra as mulheres na USF.

Com os eixos de análise estabelecidos, partimos para a elaboração dos mapas dialógicos, cuja finalidade foi nos aproximar do material, organizar os discursos e nortear as discussões a serem feitas posteriormente com a literatura. Elaboramos os mapas por acreditar que dariam visibilidade aos passos adotados no processo de análise, à dialogia presente nos discursos analisados e ao contexto de coprodução das práticas discursivas (NASCIMENTO; TAVANTI; PEREIRA, 2014).

Para os mapas, também estabelecemos duas etapas: primeiro, a construção de mapas individuais das mulheres nos quais as quatro categorias eram contempladas, a saber: a) concepções de violência contra as mulheres (VCM), b) motivações para a VCM, c) Estratégias de enfrentamento à VCM e d) atenção à VCM na USF, como no exemplo a seguir:

\section{Mapa dialógico de Margarida}

$\begin{array}{cccc}\text { Concepções de } & \text { Motivações para a } & \text { Estratégias de } & \text { Atenção à VCM } \\ \text { VCM } & \text { VCM } & \text { enfrentamento à } & \text { na USF } \\ & & \text { VCM } & \end{array}$

Posteriormente, as informações de cada mapa foram reunidas em quatro quadros gerais, nas quais as narrativas das interlocutoras foram organizadas de acordo com a temática sobre a qual versavam, de maneira que cada categoria facilitasse uma "conversa" entre todas as mulheres, resultando em quatro mapas (cada um contemplando um eixo) com 15 colunas cada (cada coluna representava as dialogias com uma interlocutora). 
Por fim, para a produção dos resultados que serão expostos a seguir, as informações coproduzidas nesse processo atravessaram e foram atravessadas por textos sobre a temática da violência contra as mulheres, em uma análise que nos permitiu compreender como as categorias se conectam e se influenciam mutuamente.

\section{ANÁLISE E DISCUSSÃo}

\section{CONCEPÇÕES DE VIOLÊNCIA CONTRAAS MULHERES}

A partir das narrativas das mulheres entrevistadas foi possível identificar as concepções a respeito do fenômeno da violência como um eixo de análise, no que diz respeito ao que essas mulheres entendem por violência contra as mulheres, partindo de relatos e exemplificação de violências.

Esta concepção difere a partir das experiências de vida das sujeitas, sejam essas situações de violência sofridas por elas ou também compartilhadas com outras mulheres, o que nos foi trazido na forma de relatos de violências experimentadas por mulheres próximas às entrevistadas, como, por exemplo, vizinhas, amigas ou familiares.

A partir da noção de concepção foi possível identificar diversos tipos de violência contra as mulheres, sendo referidos casos de violência física, sexual, doméstica, conjugal, institucional, psicológica e patrimonial. No entanto, predominou na maioria das narrativas a violência física, sexual e psicológica, como podemos visualizar nos trechos abaixo:

Entrevistadora: O que é que a senhora entende por violência? Quais são as formas?

Entrevistada: Eu acho que... dar na pessoa, fazer o sexo quando não quer... esses negoço assim... dar cantada, uma roupa que você veste...

(Amarílis)

Entrevistadora: O que tu entende por violência contra a mulher? O que tu acha que é violência contra a mulher?

Entrevistada: É, bater né? Espancar, essas coisas... Não acho certo.

Em consonância com o que nos diz Schraiber, Barros e Castilho (2010), sobre os agravos à saúde, em especial à saúde mental, de mulheres vítimas de violências, muitas das narrativas trazidas pelas entrevistadas focaram nas consequências psicológicas enfrentadas por mulheres que vivem ou viveram situações de violência.

Entrevistadora: O que você entende por violência contra a mulher? A sua concepção assim, o que você acha que é violência contra a mulher?

Entrevistada: Eu acho que é uma coisa horrível né? [...] Porque tem mulheres que ficam muito assim... Como posso dizer? Se torna assim, se torna assim, presa demais. Tem medo. Tem medo né... do companheiro. Tem medo.

(Lobélia) 
Entrevistadora: É... o que é que tu entende por violência contra a mulher Magnólia?

Entrevistada: É ruim... é sofrimento. Que não deveria existir, e que quando existe... a mulher sofre, sofre, sofre, sofre, né?

(Magnólia)

A necessidade de ampliar o olhar sobre as formas de violência foi exemplificada também em relatos de violência sofrida pelas mulheres, como no caso de uma mulher que identificou como forma de violência a pressão do seu companheiro para que ela realizasse um aborto, por não querer exercer a paternidade.

Entrevistador: É... tu já sofreu alguma violência? Tu já passou por alguma situação de violência?

Entrevistada: Violência fís... não, violência física não. Assim, tu chega pra uma pessoa, uma mulher que tá gravida, mesmo sem ter planejado e pedir... eu acho que assim, isso foi uma violência, mas física... agressão física não.

Entrevistador: Mas, então, tu compreende essa situação que tu passou como uma violência que tu sofreu?

Entrevistada: Eu acho que sim, tu chegar pra uma pessoa e pedir pra ela tomar, fazer algum procedimento, assim... pra tirar uma vida, mesmo que teja no início mas já é uma vida, eu acho que isso é uma agressão...

(Jasmim)

Outra questão importante trazida pelas interlocutoras diz respeito à hierarquia de gênero, que ao produzir desigualdades, subordina as mulheres ao poder masculino, repercutindo em seu cotidiano, tal como apontam Guedes, Silva e Fonseca (2009), o que pode ser revelado a partir da narrativa a seguir:

Entrevistador: E... o que é que tu entende por violência contra a mulher? Quando eu pergunto... o que é que vem na tua cabeça quando eu pergunto... quando tu ouve falar em violência contra a mulher?

Entrevistada: Rapaz, eu fico indignada, eu fico revoltada, porque a gente é indefesa né? Porque a gente não vai poder com um homem, tem que ceder a ele... eu mesmo, eu fico revoltada...

(Narciso)

Em outro exemplo podemos perceber como as desigualdades de gênero e o uso da violência funcionam como mecanismos de controle dos modos de vida das mulheres (GUEDES; SILVA; FONSECA, 2009).

Entrevistada: ele bateu em mim três vezes ou foi quatro vezes e ele falou que se eu prestasse queixa contra ele, ele ia se soltar, e ele tinha dinheiro pra fazer o que quiser comigo e com a minha família, eu fiquei com medo por causa da minha mãe, pensava logo na minha mãe, aí eu peguei e deixei pra lá, me separei dele.

(Magnólia)

Por fim, entendemos que as concepções de violência trazidas pelas interlocutoras dizem respeito às suas experiências e aos diversos olhares sobre o fenômeno da violência contra as mulheres, 
tais percepções não estão desconectadas do contexto em que elas se inserem no âmbito social, econômico e cultural, portanto, faz-se relevante atentar também para as motivações que levam às ocorrências de violência.

\section{MOTIVAÇÕES PARA SITUAÇÕES DE VIOLÊNCIA}

Com base na análise das entrevistas realizadas com 15 mulheres entrevistadas nas USFs algumas categorias de análise foram evidenciadas. Dessa forma, a categoria Motivações para a situação de violência se tornou um eixo de análise que buscou compreender as diversas relações de poder e opressão que estavam em torno da questão da violência doméstica e as perspectivas trazidas pelas mulheres como sendo fatores relevantes nesse processo. Pois, como já foi discutido anteriormente a desigualdade possibilita que a violência apareça como mecanismo de controle, poder e força nas relações pessoais e familiares (GUEDES; SILVA; FONSECA, 2009; RODRIGUES et al, 2012).

A questão da violência doméstica contra as mulheres tem múltiplas determinações que se relacionam entre si, tendo como solo fértil o contexto machista e patriarcal em que vivemos. As relações de poder e dominação entre homens e mulheres, colocam estas num lugar de desigualdade e vulnerabilidade dificultando a construção de relacionamentos baseados no diálogo e na horizontalidade.

Por outro lado, o caldo da cultura onde a dominação masculina tem lugar, exige dos homens o exercício da violência em suas relações afetivo-sexuais e o uso da força física para determinar o lugar das mulheres na relação e no mundo. As mulheres, por sua vez, têm poucos elementos que as possibilitem fazer deslocamentos quer sejam simbólicos ou reais dentro do relacionamento, tendo em vista que esbarram na cultura que naturaliza e legitima estas formas de violência, mesmo quando já temos a disposição diversos elementos que se colocam como contraponto ao discurso machista e patriarcal de legitimação da violência de gênero. Observemos o relato de Magnólia.

Entrevistada: Ele pegou aquela doença do rato, todo mundo aqui do posto já sabe, que ele ficou com a leptospirose, cuidei dele que só, quando foi dois meses ele veio bater em mim, bateu na minha cara, sem eu fazer nada, tava deitada, ele... começou a gritar e a chorar, eu disse "porque tu fizesse isso comigo?", ele disse "por nada, me perdoa Magnólia", eu fiquei doida da cabeça na hora, "o que foi que eu fiz?", eu não tinha feito nada, eu tava já dormindo, ele veio e meteu a mão na minha cara, me puxou pelo meu braço, e eu dizia "o que foi que eu fiz? Só quero saber o que foi que eu fiz", "nada”, aí eu peguei e me indignei dele...

(Magnólia)

Nas palavras da entrevistada fica perceptível a tentativa de atribuir algum sentido sobre a violência vivida, as mulheres muitas vezes são culpabilizadas pelas violências sofridas e neste 
sentido, buscam uma justificativa que esteja ligada a alguma ação anterior praticada por elas. Porém, como vemos acima, essa tentativa não encontra eco na realidade, pois, não existe resposta que dê conta ou justificativa a agressão vivida pelas mulheres baseada no gênero.

Por outro lado, a questão da culpabilização feminina está muito arraigada no discurso cotidiano, como pode-se ver na fala de uma das mulheres. Lobélia na tentativa de encontrar um sentido com relação as violências sofridas pelas mulheres, reproduz o discurso machista de que o corpo da mulher é responsável pela violência sofrida. Como discutido anteriormente, na cena de violência passa a operar a negação do direito sexual feminino e a dominação pelo parceiro sobre o corpo e o desejo da mulher. (GUEDES; SILVA; FONSECA, 2009).

Entrevistada: Bem...Também as mulheres andam nuas, as assistente... muita mulher anda nua, pedindo pra ser, pra ser agredida mesmo, porque o homem passa a mão numa bunda de uma deles porque elas tão com um shortzinho que só cobre mesmo a... a polpa da bunda, num é não? Eu acho mesmo que é por causa disso.

(Lobélia)

Rosa também traz a questão da mulher como culpada em seu discurso, segundo ela, a mulher muitas vezes é agredida em decorrência das escolhas erradas que realizou.

Entrevistada: Assim, como eu te disse, né? Muitas procuram, né? Muitas se envolvem com tráfico, muitas se envolvem com pessoas erradas, muitas mulheres... muitas são brabas... então, assim, quem procura acha né?

(Rosa)

O estudo realizado por Lima et al. (2013) fala da autoestima das mulheres relacionada a valorização por parte do parceiro e aos enfrentamentos que conseguem realizar frente a violência. Nas entrevistas percebemos a dificuldade que a mulher tem para lidar com a violência, verbalizá-la, visibilizá-la e enfrentá-la, tendo em vista que elas aprendem que está e uma experiência do privado, que diz respeito exclusivamente a ela, como se esta vivência não fosse coletiva, como se não estivesse relacionada a experiência de ser mulher na sociedade. Essa noção de particularidade da violência pode ser vista no relato abaixo.

Entrevistador: E... tu acha que o posto é um lugar que as mulheres procuram pra falar de violência?

Entrevistada: Não, eu acho que não. Eu acho que as mulheres elas guarda pra si mesma, tanto por causa da vergonha, e até mesmo ameça dos próprios maridos, dentro de casa.

(Rosa)

Algumas mulheres ainda reconhecem o racismo como mais um elemento gerador de violência contra as mulheres, quando são questionadas se as mulheres negras são mais vulneráveis à violência que as mulheres brancas. Nesse sentido uma das mulheres nos diz o seguinte: 
Entrevistada: Eu acho que... é. Eu acho que hoje em dia está mais as morenas, né? As negras, né? Pelo racismo, né? Apesar que graças a deus eu não tenho racismo, porque minha filha é morena. Mas tá muito mais pelo racismo de hoje em dia.

(Narciso)

Diante disso, pode-se perceber muitos fatores que se colocam como disparadores e/ou justificadores da situação de violência, a compreensão destes nos permite entender as diferentes realidades de vidas destas mulheres e perceber como as várias vulnerabilidades se interseccionam e dão lugar a violência.

\section{ESTRATÉGIAS DE ENFRENTAMENTO À VIOLÊNCIA CONTRA AS MULHERES}

Recorrendo a Vieira et al. (2011), entendemos que o olhar para as estratégias utilizadas pelas mulheres para rompimento do ciclo de violência, deve levar em consideração o contexto de sua trajetória de vida e de seu cotidiano, dos laços sócio-afetivos estabelecidos e dos diferentes papéis que exerce no seu contexto social.

Desta forma, as participantes da pesquisa em questão, elencaram a partir de suas concepções e vivências, estratégias de enfrentamento da violência contra às mulheres, das quais, nomeamos em três blocos: rede de apoio sócio afetiva, justiça e serviço de saúde.

Ao tratar da rede de apoio sócio afetiva, identificamos nesta pesquisa, relatos referentes às relações de parentesco e de amizade, como estratégias que se configuram como o primeiro apoio para tomada de decisão ou como principal sustentação para saída do ciclo de violência.

Tais observações são evidenciadas através das narrativas:

Entrevistada: No meu caso eu conversaria com uma amiga muito amiga mesmo, e depois procuraria o serviço. Caso eu não tivesse uma amiga, ia direto no serviço mesmo

(Amarilis)

Entrevistada: A casa né? Pra família, em primeiro lugar, pra dar um apoio né? Porque a pessoa sem a família pra não dar apoio não é nada

(Narciso)

Outro relato nos mostra que a rede de apoio sócio-afetiva traz repercussões positivas para o rompimento do ciclo de violência, quando ampliada, levando em consideração as diferentes relações que atravessam a vida, a saber:

Entrevistada: Os familiares dela, sempre presente, as amigas, dando conselho, ajudando... Aí ela foi esquecendo, esquecendo... Aí... 
Magnólia de 33 anos, assim como as outras participantes da pesquisa, relata a família como um apoio importante para a tomada de decisão quanto ao rompimento do ciclo de violência.

Entrevistada: Mas depois eu botei na minha cabeça é melhor ficar na casa da minha mãe. Ficar dormindo no chão ou no sofá e ninguém bater em mim. Viver na paz do que viver aqui, ter minhas coisas e viver apanhando. Aí peguei e fui embora, deixei as coisas e fui embora... Resumindo, botei na justiça, botei pra ele dar cem reais ao menino. Eu tava trabalhando, tava ótimo né? Agora não sei como vai ser. Mas na minha casa... Na casa da minha mãe ninguém passa fome não, graças a Deus.

(Magnólia)

Observamos na narrativa supracitada, outros condicionantes que complexificam a experiência da violência vivenciada, como por exemplo, as limitações financeiras e de condições de vida abordadas pela participante da pesquisa. Tal evidência, pode ser relacionada ao que Meneghel et al. (2011) descrevem como "rota crítica", tratando dos fatores facilitadores e inibidores da decisão de romper com as violências.

Outro elemento evidenciado pelo relato de Magnólia é a justiça como estratégia, o que vai ser ratificado pela maioria das participantes da pesquisa. Nomeamos como justiça, o que as entrevistadas identificam como polícia, delegacia/ delegacia das mulheres e a Lei Maria da Penha (BRASIL, 2006). Em relação à Lei, encontramos:

Entrevistada: Tem que procurar né? Procurar uma lei, tem que ter uma lei pra poder acabar com isso, com essa violência... Uma pessoa assim, que pudesse resolver, uma lei que pudesse resolver esses casos...

(Lobélia)

Embora a maior parte das mulheres façam referência à Lei como um dispositivo de proteção, nos chamou atenção o fato de uma das entrevistadas atribuir à Lei o aumento do feminicídio 3 :

Entrevistada: ...Do jeito que saiu essa Lei Maria da Penha, eu acho que veio mais pra foder as mulher mesmo, botar pra ferrar, porque antes dessa lei os caras não matavam, e agora que saiu essa lei é que eles dizem assim - se eu não fizer eu vou preso e se eu fizer eu vou preso

(Narciso)

Esta última narrativa nos remete ao discurso de uma outra entrevistada que vai referir o medo como inibidor da denúncia:

Entrevistada: Pra quem é vítima devia fazer a queixa né? Procurar seu direito... Sempre tá dando queixa alertar outras pessoas né? Porque tem mulher que tem medo de dar queixa...

\footnotetext{
${ }^{3}$ Homicídio qualificado contra a mulher por razões da condição de sexo feminino (BRASIL, 2015).
} 
Ao analisar as entrevistas, identificamos como outro elemento que dificulta a efetivação da denúncia, o movimento de culpabilização das mulheres em situação de violências, seja por elas próprias, sociedade ou pela polícia.

Entrevistada: Procurar a polícia, procurar a delegacia, prestar uma queixa... ver também se ela errou, onde foi que ela errou, porque ninguém vai chegar e bater por nada, sempre tem alguma coisa né? Então assim... mas ela tem que manter-se né, certa no caminho

Entrevistada: Não, o posto num se mete não. Nem posto, nem ninguém se mete não. Eu chamei a policia duas vezes, mas, os policial num presta não, não suporto policia, porque a gente chamou a policia, e o policial conversou comigo e disse "pense direitinho, viu? Porque é melhor você assinar um B.O." porque... eu nem sabia o que era B.O., ele que me explicou lá, "porque se você assinar aqui pra ele descer", com aquele negoço da maria da penha..."Ele pode descer, agora pense direitinho porque você tem um filho pra criar, você vai criar esse filho só, e ele chegar lá vai ser tratado como bandido, e pelo que eu percebi..." ele nem tinha visto ele ainda, "pelo que to percebendo nem você é errada, nem ele é errado", aí eu disse "e você viu, por um acaso, ele? Você primeiro tem que ver ele pra depois você falar", aí ele disse "não, mas ele não deve ser um bandido", ouxente, e bandido não bate... homem certo não bate em mulher não? Assim, tipo assim, ele quis dizer que quem bate em mulher é que era bandido, entendesse? Não, era assim não, porque ele falou assim... eu falei assim, porque que, meu ex-marido não é um bandido entendeu? (...) Tipo, a gente vai dizer assim: vai chegar, fulano bateu em mim. Ah! mas tu é safada, merece apanhar, tu não presta, porque se prestasse já tinha deixado, já tinha prestado queixa. Mas a gente vai prestar queixa pra quando ele se soltar ir lá e matar a gente. É melhor deixar pra lá.

(Magnólia)

Neste último relato, voltamos a identificar o medo como um sentimento sempre presente no cotidiano das mulheres e forte associação deste com a culpabilização.

Um outro aspecto observado foi de que algumas mulheres, fazendo referência a violência por parceiro íntimo, constroem certa lógica para organização das estratégias de enfrentamento, que estão, ao nosso ver, associadas às questões subjetivas de cada entrevistada.

Entrevistada: Deve conversar. Perguntar a ele se ele aceita ir pra um lugar que possa orientar eles a conversar pra que aquilo não ocorra mais. E se realmente ele não aceitar ou não correr... Eu acho que ela tem que buscar um apoio, buscar um modo de não continuar com aquilo, não virar uma rotina aquela agressão contra ela, né? Independente se tenha filho, se não tenha, eu acho que mulher nenhuma deve aceitar ser agredida por ninguém.

(Jasmim)

Entrevistada: Eu acho que depende muito assim, da situação, porque se for marido dela eu acho que ela vai pensar duas vezes antes de denunciar. E se ela tiver chegado no limite dela eu acho que denuncia. Eu, na verdade, se fosse comigo eu não aceitaria, eu não aceitaria isso não. Graças a deus meu marido nunca inventou de levantar a mão pra mim, mas, num sei assim, pra pessoa... outra pessoa denunciar... só se for anônimo... se for um caso muito grave, muito extremo mesmo, aí eu acho que deveria denunciar

(Anis)

Os achados nesta pesquisa nos mostram diferentes dimensões envolvidas na experiência das situações de violência, demandando, conforme sinaliza Vianna, Bonfim e Chicone (2006), um olhar interdisciplinar e intersetorial, para além da justiça. Neste sentido, outros setores como a saúde, 
especialmente a atenção primária, são fundamentais para abordagem da temática nas comunidades, através de ações de prevenção e promoção da saúde (D’OLIVEIRA et al., 2009).

As participantes elencaram algumas ações que podem ser realizadas nas unidades de saúde:

Entrevistada: Se... Assim, né, cartazes, sei lá... alguma coisa, tipo o agente de saúde ir na casa, fazer um... tipo um mutirão, fazer uma roda de conversa, uma mesa redonda e tal, falar sobre isso...

(Margarida)

Entrevistada: Que no posto sempre botassem uma equipe, uns profissionais pra fazer... não só quando tivesse campanha, mas que botasse pelo menos frequentemente, uma vez no mês... ia melhorar bastante, porque muita mulher ia se identificar e ia la, né, pra conversar com os profissionais... poderia até evitar muitas mortes, né?

(Rosa)

Os relatos supracitados confirmam as ideias de Vianna, Bomfim e Chicone (2006), quanto às possibilidades de estratégias que podem ser ofertadas pela Unidade de Saúde da Família (USF).

Observamos que algumas entrevistadas fazem referência à busca pelo setor saúde apenas para violência física, fazendo certa classificação de gravidade e fragmentando as situações de violência vivenciadas.

Entrevistada: Eu acho que ela ia primeiro no hospital mesmo, posto eu acho que o pessoal nem procura, procura mesmo o hospital... a não ser que a violência seja fraquinha, aí vai ao posto, mas quando é violência grande vai direto pro hospital

(Amarilis)

Entrevistada: ...Não vêm a necessidade de procurar o posto, a não ser que for ao posto assim... Que tiver muito grave, for um ferimento, que precisar de um curativo, né? Alguma coisa assim

(Lobélia)

Numa análise mais geral dos relatos, fica clara a necessidade de ampliar o olhar sobre a questão da violência, para além dos aspectos biológicos, compreendendo a rede de relações sociais que a mulher estabelece (VIEIRA et al., 2011).

\section{ATENÇÃO ÀS VIOLÊNCIAS CONTRA AS MULHERES NA USF}

A partir das narrativas das mulheres entrevistadas foi possível identificar a atenção que é dada à violência contra as mulheres dentro da USF, esse eixo diz respeito de como está a resolutividade, o atendimento e ações sobre violência contra as mulheres dentro da Unidade de Saúde da Família.

D’Oliveira et al. (2009), apontam a importância de investigar a violência nos serviços de saúde, para que o fenômeno e a situação possam ser melhor compreendidos, físico, emocional e socialmente, e melhores estratégias e práticas de cuidado integral possam ser desenvolvidas.

Quando perguntada se os profissionais perguntam sobre violência ou sobre questões pessoais durantes os atendimentos, a entrevistada responde: 
Entrevistada: Perguntam nada, eu acho que não. Pelo menos a mim ninguém nunca perguntou não

(Hortência)

Como sugerem Lyra et al. (2016), torna-se importante que o atendimento da equipe de saúde possa ir além dos cuidados médico-curativo, compreendendo o contexto no qual a mulher está inserida e realizando encaminhamentos adequados.

As respostas de Magnólia quando perguntada se costuma levar questões da vida pessoal para os atendimentos no posto de saúde e como ela se sente durante esses atendimentos também corroboram a importância de atendimentos que vão além dos cuidados médicos-curativos:

Entrevistada: Muito bem, ela conversa muito, muito bem comigo. Muita coisa da minha vida [...] Principalmente quando eu era casada que eu apanhava do meu ex-marido, aí conversava muito com ela, chorava muito com ela, com a doutora, gosto muito, muito dela

(Magnólia)

Ao ser perguntada sobre o que poderia ser feito no posto para tratar da questão da violência com as mulheres, a entrevistada diz:

Entrevistada: Ter reunião, né? Ter um grupo dedicado só a isso... como tem o grupo de hipertenso, deveria ter um grupo contra violência... mas as vezes tem grupo e ninguém vai, que ninguém quer se expor e dizer que apanha do marido, que faz isso e aquilo outro...

(Amarílis)

O sentido que essa mulher constrói afirma a importância de ações específicas proporcionadas pela Unidade de Saúde da Família sobre o tema da violência, ao mesmo passo em que ratifica as afirmações de Schraiber, D’Oliveira e Couto (2006), de que a não identificação do fenômeno da violência durante os diagnósticos relaciona-se às dificuldades das mulheres na revelação do vivido, essa dificuldade é reforçada em muitos casos pelo descrédito e julgamento moral dos profissionais que as escutam.

Magnólia traz em sua fala experiências positivas de atendimentos, refere-se a uma ação construída pela unidade de saúde da família em parceria com a comunidade como exemplo de espaço em que as pessoas não se sentem julgadas, elemento que Schraiber, D'Oliveira e Couto (2006) pontua como essencial a escuta e identificação de situações de violência.

Ao ser questionada sobre a existência de algum espaço ou atividade que o pessoal da unidade faz para as pessoas poderem compartilhar questões pessoais, ela responde:

Entrevistada: Terapia do bambu é uma... é o pessoal da comunidade com o pessoal daqui do posto, a sala enchia, era uma sala maior que essa daqui, bem maior, aí rodiava de gente 
assim, aí se eu tivesse algum problema, se eu tivesse passando por alguma coisa conversava, aí alguém dava uma opinião... num ia criticar

(Magnólia)

De acordo com Soares, Lopes e Njaine (2013), as estratégias para enfrentamento das múltiplas violências cometidas contra as mulheres devem ser construídas sob a ótica da valorização da integração comunitária, e a finalidade do trabalho contra as violências deve caminhar em direção ao empoderamento das mulheres, sua emancipação e autonomia, não apenas o tratamento dos sintomas e a resolução das queixas com práticas de medicalização, reorientando a base do trabalho do profissional de saúde.

Entrevistador: E... tu acha que o posto é um lugar que as mulheres procuram pra falar de violência?

Entrevistada: Não, eu acho que não. Eu acho que as mulheres elas guarda pra si mesma, tanto por causa da vergonha, e até mesmo ameaça dos próprios maridos, dentro de casa.

(Rosa)

No que se referem a situações de violência vivenciadas pelas mulheres essas, raramente aparecem de forma imediata no serviço, sendo expressas como demanda implícita. Assim, entendemos que a atenção a violência contra as mulheres dentro das Unidades de Saúde, é o olhar e as experiências que as mulheres vivenciaram durante sua ida a USF e a sua confiança em falar sobre aspectos considerados de cunho pessoal para os profissionais que ali atendem.

\section{ALGUMAS CONSIDERAÇÕES}

A USF por se configurar como porta de entrada do Sistema Único de Saúde (SUS) e trabalhar sob a lógica da territorialidade apresenta características privilegiadas para ações de enfrentamento à violência contra as mulheres, uma vez que estes/as profissionais se encontram inseridos na comunidade e suas práticas de cuidado devem estar pautadas na escuta qualificada dos/as usuários/as e construção de vínculos que potencialize todas as intervenções realizadas.

$\mathrm{Na}$ pesquisa realizada verificamos que as entrevistadas, em sua maioria, relataram dificuldades para falar de "questões de sua vida" durante os atendimentos realizados nas unidades de saúde, especial, sobre a violência. $\mathrm{O}$ atendimento às mulheres que sofreram violência deve ir além da oferta de condutas e procedimentos demandados, pois implica a cumplicidade do profissional, e no seu empenho pessoal e ideológico com o rompimento da condição de opressão de gênero que perpetua a violência.

Observamos que, na maioria das vezes, as situações de violência não são percebidas/dialogadas pelos/as profissionais e usuárias nos atendimentos individuais e/ou ações 
coletivas, porém neste último algumas entrevistadas relataram palestras e campanhas pontuais sobre a temática da violência contra as mulheres . Ao não perguntar as usuárias sobre situações de violência e/ou outros aspectos de sua trajetória além de agravos físicos os/as profissionais podem restringir seu atendimento a um modelo biologizante desconsiderando, muitas vezes, situações experienciadas pelas usuárias que podem levar a sofrimento psicológico, isolamento social, problemas econômicos, dores de cabeça, tentativas de suicídio etc.

A dificuldade de identificação dos casos de violência pelos serviços depara-se muitas vezes com a inexistência do tema em grande parte dos currículos dos profissionais de saúde. Fazendo com que muitos deles não consigam identificar os casos de violência com que se deparam ou mesmo utilizar as estratégias necessárias nos casos em que o fenômeno se torna visível.

As entrevistadas pontuaram algumas estratégias como grupos de mulheres, rodas de conversa, palestras e campanhas como espaços potenciais para a discussão e intervenções sobre violência contra as mulheres dentro da unidade de saúde. Ao mesmo tempo em que a maioria das participantes não percebe a USF como um espaço onde o tema da violência contra as mulheres possa ser trabalhado, pontuam a reestruturação de atividades pontuais a exemplo das campanhas e palestras para ações mais sistemáticas e que as mulheres possam ser protagonistas ao narrar as situações que vivenciam, sejam elas de violência ou não.

Este trabalho nos leva a refletir que deve haver a discussão da temática da violência contra as mulheres dentro das USF e o reconhecimento que essas unidades são o primeiro lugar que as mulheres buscam para realização do cuidado. Deve-se também compreender as dificuldades que as mulheres encontram em expor a violência sofrida, reconhecendo como um problema de saúde pública.

\section{REFERÊNCIAS}

AZAMBUJA, Mariana Porto Ruwer de and NOGUEIRA, Conceição. Introdução à violência contra as mulheres como um problema de direitos humanos e de saúde pública. Saúde soc. [online]. vol.17, n.3, pp. 101-112, 2008.

BRASIL. Presidência da República. Lei no 11.340, de 7 de agosto de 2006. (Lei Maria da Penha). Cria mecanismos para coibir a violência doméstica e familiar contra a mulher... Disponível em: http://www.planalto.gov.br/ccivil_03/_ato2004-2006/2006/lei/111340.htm. Acesso em: 20 de maio 2015.

BRASIL, Presidência da República. Lei nº 13.104, de 9 de março de 2015. Brasília, 2015. 
BRASIL. Ministério da Saúde. Secretaria de Atenção à Saúde. Núcleo Técnico da Política Nacional de Humanização. Acolhimento nas práticas de produção de saúde / Ministério da Saúde, Secretaria de Atenção à Saúde, Núcleo Técnico da Política Nacional de Humanização. - 2. ed. 5. reimp. - Brasília: Editora do Ministério da Saúde, 2010.

BRASIL. Ministério da Saúde. Secretaria de Atenção à Saúde. Departamento de Atenção Básica. Política Nacional de Atenção Básica / Ministério da Saúde. Secretaria de Atenção à Saúde. Departamento de Atenção Básica. - Brasília: Ministério da Saúde, 2012.

BRASIL. Ministério da Saúde. Secretaria de Atenção à Saúde. Departamento de ações programáticas e estratégicas. Política Nacional de Atenção Integral à saúde da mulher: princípios e diretrizes / Ministério da Saúde. Secretaria de Atenção à Saúde. Departamento de ações programáticas e estratégicas. - Brasília: Ministério da Saúde, 2004.

D'OLIVEIRA, Ana Flávia Pires Lucas et al. Atenção integral à saúde de mulheres em situação de violência de gênero: uma alternativa para a atenção primária em saúde. Ciênc. saúde coletiva [online]. vol.14, n.4, pp. 1037-1050, 2009.

FACURI, Cláudia de Oliveira et al. Violência sexual: estudo descritivo sobre as vítimas e o atendimento em um serviço universitário de referência no Estado de São Paulo, Brasil. Cadernos de Saúde Pública, 2013.

FLICK, Uwe. Entrevista episódica. MW Bauer \& G. Gaskell, G.(Orgs.), Pesquisa qualitativa com texto, imagem e som: um manual prático, p. 114-136, 2002.

GUEDES, Rebeca Nunes; FONSECA, Rosa Maria Godoy Serpa da; EGRY, Emiko Yoshikawa. Limites e possibilidades avaliativas da estratégia saúde da família para a violência de gênero. Rev. esc. enferm. USP [online]. vol.47, n.2, pp. 304-311, 2013.

GUEDES, Rebeca; SILVA, Ana Tereza; FONSECA, Rosa Maria. A violência de gênero e o processo saúde-doença das mulheres. Escola Anna Nery, v. 13, n. 3, p. 625-631, jul./set. 2009.

ILHA, Michele Mazza; LEAL, Sandra Maria Cezar.; SOARES, Joannie dos Santos Fachinelli. Mulheres internadas por agressão em um hospital de pronto socorro:(in) visibilidade da violência. Revista Gaúcha de Enfermagem, v. 31, n. 2, p. 328, 2010.

KRUG, Etienne et al. World on Violence na Health: Sumary. Geneva: World Health Organization, 2002. 
LIMA, Jamile Santana et al. Autoestima e estratégias de enfrentamento de mulheres que sofrem violência doméstica: uma experiência de diagnóstico participativo. In: Encontro Revista de Psicologia, vol. 16, n 24, p. 43-53, 2013.

LYRA, Jorge et al. Avaliação da atenção às mulheres em situação de violência na rede de atenção básica em saúde no município de Recife. Relatório Técnico Final. Recife: UFPE, 2016. (mimeo). Pesquisa financiada pelo Edital: APQ - 13/2012 - pesquisa para o SUS: gestão compartilhada em saúde PPSUS - REDE MS/CNPQ/FACEPE/SES - $2^{\mathrm{a}}$ rodada. Processo $\mathrm{N}^{\mathrm{o}}$ : APQ 0023-4.00/13.

MEDRADO, Benedito; LYRA, Jorge. Entrevistas e outros textos: compartilhando estratégias de análise qualitativa. In: LANG, Charles E.; BERNARDES, Jefferson S.; RIBEIRO, Maria Auxiliadora T.; ZANOTTI, Susane V. (Orgs.). Metodologias: Pesquisas em saúde, clínica e práticas psicológicas. Maceió: EDUFAL, p. 85-118, 2015.

MENEGHEL, Stela Nazareth et al. Rotas críticas de mulheres em situação de violência: depoimentos de mulheres e operadores em Porto Alegre, Rio Grande do Sul, Brasil. Cadernos de saúde pública: Reports in public health. Vol. 27, n. 4, p. 743-752, 2011.

MORAES, Claudia Leite; ARANA, Flávia Dias Nogueira; REICHENHEIM, Michael Eduardo. Violência física entre parceiros íntimos na gestação como fator de risco para a má qualidade do pré-natal. Rev. Saúde Pública [online]. v. 44, n.4, pp. 667-676, 2010.

NASCIMENTO, Vanda Lúcia Vitoriano do; TAVANTI, Roberth Miniguine; PEREIRA, Camila Claudino Quina. O uso de mapas dialógicos como recurso analítico em pesquisas científicas. In: SPINK, Mary Jane; BRIGAGÃO, Jacqueline; NASCIMENTO, Vanda; CORDEIRO, Mariana (orgs.). A produção de informação na pesquisa social: compartilhando ferramentas. Rio de Janeiro: Centro Edelstein de Pesquisas Sociais, 2014.

RIVARA, Frederick et al. Healthcare Utilization and Cost for Women with History of Intimate Partner Violence. Am J Prev Med. v. 32, n. 2, p. 89-96, 2007.

RODRIGUES, Celeste de Souza et al. Acidentes e violências entre mulheres atendidas em Serviços de Emergência Sentinela-Brasil, 2009. Ciênc. saúde coletiva, v. 17, n. 9, p. 2319-2329, 2012.

SCHRAIBER, Lilia Blima. Violência contra as mulheres e políticas de saúde no Brasil: o que podem fazer os serviços de saúde?. Revista USP, n. 51, p. 104-113, 2001.

SCHRAIBER, Lilia Blima; D’OLIVEIRA, Ana Flávia; COUTO, Márcia Thereza. Violência e saúde: estudos científicos recentes. Rev Saúde Pública, v. 40 (N Esp), p. 112-20, 2006. 
SCHRAIBER, Lilia Blima et al. Violência contra mulheres entre usuárias de serviços públicos de saúde da Grande São Paulo. Rev. Saúde Pública [online]. vol.41, n.3, pp. 359-367, 2007.

SCHRAIBER, Lilia Blima; BARROS, Cláudia Renata dos Santos e CASTILHO, Euclides Ayres de. Violência contra as mulheres por parceiros íntimos: usos de serviços de saúde. Rev. bras. epidemiol. [online]. vol.13, n.2, pp. 237-245, 2010.

SOARES, Joannie dos Santos Fachinelli; LOPES, Marta Julia Marques; NJAINE, Kathie. Violência nos relacionamentos afetivo-sexuais entre adolescentes de Porto Alegre, Rio Grande do Sul, Brasil: busca de ajuda e rede de apoio. Cad. Saúde Pública [online]. vol.29, n.6, pp. 1121-1130, 2013.

SPINK, Mary Jane. Linguagem e produção de sentidos no cotidiano [online]. Rio de Janeiro: Centro Edelstein de Pesquisas Sociais, 2010. Disponível em: $<$ http://static.scielo.org/scielobooks/w9q43/pdf/spink-9788579820465.pdf $>$. Acesso em: $08 \mathrm{de}$ setembro de 2015.

SPINK, Mary Jane; LIMA, Helena. Rigor e visibilidade: a explicitação dos passos da interpretação. In: SPINK, Mary Jane (Org.). Práticas discursivas e produção de sentidos no cotidiano. (online). Edição virtual, 2013.

VIANNA, Lucila Amaral Carneiro; BOMFIM, Graziela Fernanda Teodoro; CHICONE, Gisele. Autoestima de las mujeres que sufrieron violências. Rev Lat Am Enfermagem. vol. 14, n. 5, pp. 695-701, 2006.

VIEIRA, Letícia Becker et al. Perspectivas para o cuidado de enfermagem às mulheres que denunciam a violência vivida. Esc. Anna Nery Rev. Enferm. vol. 15, n. 4, pp. 678-685, 2011.

\begin{tabular}{cl}
\hline \multirow{2}{*}{ Histórico } & Recebido em: 8-5-2018 \\
& Revisado em: 25-6-2018 \\
& Aceito em: $24-9-2018$ \\
& Fundação de Amparo a Pesquisa de Pernambuco - FACEPE \\
Financiamento & Edital: APQ - 13/2012 - pesquisa para o SUS: gestão compartilhada em saúde PPSUS - REDE \\
& MS/CNPQ/FACEPE/SES - 2 $2^{\mathrm{a}}$ rodada. Processo $N^{\circ}$ : APQ - 0023-4.00/13.
\end{tabular}

